\title{
An Empirical Study on the Agglomeration Characteristics of China's Construction Industry Based on Spatial Autocorrelation and Spatiotemporal Transition
}

\author{
Likun Zhao, Junsen Tian $(\mathbb{D}$, Yanqi Liu, and Rui Liu \\ Department of Civil Engineering, North China University of Technology, Beijing 100144, China \\ Correspondence should be addressed to Junsen Tian; 1412026763@qq.com
}

Received 28 January 2021; Revised 29 March 2021; Accepted 2 April 2021; Published 13 April 2021

Academic Editor: Hou-Sheng Su

Copyright (c) 2021 Likun Zhao et al. This is an open access article distributed under the Creative Commons Attribution License, which permits unrestricted use, distribution, and reproduction in any medium, provided the original work is properly cited.

\begin{abstract}
The spatiotemporal agglomeration of industries is the most prominent geographical feature of economic activities. Based on the analysis of the spatiotemporal distribution of China's construction industry agglomeration, this paper analyzes the characteristics and evolution trend of the spatiotemporal agglomeration of construction industry in 31 provinces and cities of China from 2010 to 2019 by using Moran's index and the spatiotemporal transition measurement model. The findings are as follows: (1) China's construction industry has experienced two stages in terms of time: steady rise and turbulent rise. Spatially, China's construction industry, as a whole, the space takes the shape of one horizontal and two vertical, similar to the letter " $\mathrm{H}$ " being crossed. And the difference of "East-West" two ends of the industrial agglomeration level is obvious. (2) The Yangtze River Delta Urban Agglomerations (Shanghai, Jiangsu, and Zhejiang), the Pearl River Delta Urban Agglomerations (Guangdong), Beijing-TianjinHebei Urban Agglomerations, and the western region (Xinjiang and Tibet) have significant local features. The four major types of China's construction industry cluster, which are H-H, H-L, L-H, and L-L, are formed. (3) The time-space transition of China's construction industry is dominated by the "stable transition" mode. The transition inertia is significant. The regional development has strong path dependence and spatial locking characteristics.
\end{abstract}

\section{Introduction}

Industrial geographic agglomeration is one of the significant characteristics of industrial spatial distribution. According to statistics, in France, the United Kingdom, and the United States, $75-95 \%$ of industrial production activities have been centralized, and the proportion of decentralized production activities is less than 15\% (Maurel, 1999; Wen, 2004) [1, 2]. However, once industrial agglomeration is formed, it will not be fixed forever. When the industry gathers to a certain extent, the crowding cost will be generated, thus forming the centrifugal force to promote the industry outward transfer.

At present, the research on the temporal and spatial evolution of industrial agglomeration and the measurement of agglomeration level mainly focuses on the overall level of manufacturing industry, while the research on the evolution of space-time pattern of industrial agglomeration and the measurement of agglomeration level is less.

As for the research on the spatiotemporal evolution of industrial agglomeration, Krugman (1991) and Fujita et al. (1999) established FKV model to explain the spatial agglomeration phenomenon of industrial activities in the 1990s [3, 4]. Dirk (2006) and Ikeda et al. (2016) extended the clustering model to the geographical dimension and depicted the scale of spatial clustering area through endogenous changes in location $[5,6]$. In addition, Hoffmann et al. (2017), Zhao et al. (2019), and Hu et al. (2019) analyzed the spatial clustering phenomenon in the service industry and other fields by using clustering index and other methods [7-10]. However, most statistics used to detect industrial spatial agglomeration cannot distinguish high and low spatial clustering. In order to fill this gap, Zhang and Lin (2010) introduced Moran's index to simulate the evolution 
characteristics of real spatial agglomeration pattern [11], and Kang (2010) determined the spatiotemporal clustering threshold of agglomeration process based on Zhang [12]. The scholars comprehensively analyzed the agglomeration pattern of agriculture (Li, 2020; Zhao et al., 2019), manufacturing (He and Xie, 2006; Yi and Zhang, 2020), and service (Zhang et al., 2013; Li et al., 2019) by using relevant spatial statistical analysis methods [13-20]. Among them, some scholars also discussed the spatial clustering characteristics of the architectural industry (Tong et al., 2012; Sun et al., 2015; and Zhao et al., 2021) [21-23].

Measure study on industrial agglomeration level and single industrial concentration measurement method has a lot of literature research; there are mainly location entropy (Xie et al., 2015) [24], industrial geographical concentration (Chris and Declan, 2013) [25], Herfindahl-Hirschman index (Bruckmann, 1971) [26], locational Gini-coefficient (Dagum, 1986) [27], E-G index (Ellison and Glaeser, 1999) [28], multivariable intelligent analysis ( $\mathrm{Su}$ et al., 2019; Su et al., 2020) [29, 30], $K$ function (Ripley, 1977) [31], D-O index (Yuan et al., 2014) [32], Moran's I (Moran, 1950) [33], and Standard Deviational Ellipse (Wong, 1999) [34]. The research on common agglomeration measurement method is relatively late. Duranton and Overman (2008), Marcon and Puech (2009), and Lang et al. (2015), respectively, proposed the corresponding common agglomeration measure methods based on $K$ function and $M$ function (Overman, 2005) [35-38]. On the foundation of the study of Howard's coclustering index (Howard et al., 2016) [39], Kopczewska (2016) proposed a distance-based coclustering index [40]. Liu et al. used the above method to measure the spatial agglomeration level of manufacturing industry and other industries (Zheng, 2012; Qiu and Fang, 2013; Guo and Zhang, 2017; and Liu, 2019) [41-44].

It is found by the above literatures that the researches on theoretical innovation in foreign countries and China are relatively late. In the aspect of industrial agglomeration level and characteristics, the systematic results have not been formed. The research field mainly focuses on manufacturing, service industry, and agriculture, while the construction industry is involved less and mainly stays at the level of industrial development status. Few scholars have studied the spatial evolution characteristics of the building industry agglomeration, lacking analysis on spatial correlation and heterogeneity of the building industry.

Based on the building output value of panel data from China's 31 provinces, autonomous regions, and municipalities directly under the Central Government and Xinjiang Production and Construction Corps (excluding Hong Kong, Macao, and Taiwan) from 2010 to 2019, this paper uses spatial autocorrelation analysis to analyze the spatial agglomeration pattern of China's construction industry. Based on the LISA spatiotemporal transition analysis framework proposed by Rey et al., with the help of the comprehensive advantages of geography, this paper discusses the dynamic evolution of the local construction industry's spatial development. This study's conclusions have thoroughly investigated the temporal and spatial evolution characteristics of the agglomeration of the construction industry in China.
The results of the study not only provide a data basis for the evaluation of the agglomeration development of the construction industry in China but also help to verify the implementation effects of the construction industry agglomeration policies and measures and determine the focus of future construction industry development regions and breakthrough points that enrich the theory of agglomeration of the construction industry. When discussing its regional differences and spatial structure, the time attribute and space attribute are combined, which more comprehensively reveals the dynamic differentiation law of the development of the construction industry and provides theoretical analysis of spatial economics and new economic geography to develop the construction industry perspective.

\section{Modeling and Data Sources}

2.1. Modeling. The empirical study on the spatiotemporal characteristics of China's construction industry agglomeration is divided into two parts: (1) The spatial and temporal distribution of construction industry is analyzed by natural breakpoint method. (2) Based on the spatiotemporal transition measure model and the global Moran's index and the local Moran's index in ESDA model, the spatial agglomeration characteristics of construction industry are summarized.

2.1.1. Spatial and Temporal Distribution Econometric Model of ArcGIS. The natural segment point method (Jenks, 1967) is a method of classifying data sets [45]. ArcGIS software was used to calculate the proportion of the output value of construction industry in 31 regions of China in the national output value of construction industry. The classification was carried out according to the natural segment point method, and the distribution of geographical space was analyzed. According to the natural segment point method, this article divides the indicators into five levels. The proportions of the representatives from the first to the fifth level are arranged from low to high as follows:

Grade 1:0.001-0.009

Grade 2: 0.009-0.024

Grade 3: 0.024-0.048

Grade 4: 0.048-0.082

Grade 5: 0.082-0.133

2.1.2. Spatial Autocorrelation Analysis Model of Spatial Agglomeration Characteristics. Moran's index is an important index to measure spatial correlation which includes the global Moran's index and the Anselin local Moran's index. The range of Moran's index is $[-1,1]$. Moran's index $>0$ means positive spatial correlation. The larger the value is, the more obvious the spatial correlation is. Moran's index $<0$ means negative spatial correlation. The smaller the value is, the greater the spatial difference is Moran index $=0$; the spatial distribution is random. 
In this paper, Moran's index is introduced to analyze the spatial correlation and dependence between construction industry clusters in China's neighboring regions:

(1) The Global Moran's Index. The global Moran's index (Anselin, 1995) describes the spatial characteristics of the construction industry development in the whole region [46]. It judges whether there is spatial agglomeration in the development of the construction industry. This is shown in the following formula:

$$
I=\frac{\left(n \sum_{i=1}^{n} \sum_{j=1}^{n} w_{i j}\left(x_{i}-\bar{x}\right)\left(x_{j}-\bar{x}\right)\right)}{\sum_{i=1}^{n} \sum_{j=1}^{n} w_{i j} \sum_{i=1}^{n}\left(x_{i}-\bar{x}\right)}
$$

where Moran's index is the global spatial autocorrelation index of construction industry development. $n$ is the 31 regions of China. $X_{i}$ is the regional construction output value. $X_{i}$ is the average value of construction output value. $X_{i}$ is the spatial weight, which represents the potential interaction between regional construction industry development under the given significant level. Due to the special geographical location of Hainan, it is assumed that Hainan Province is adjacent to Guangdong Province and Guangxi Province.

(2) The Anselin Local Moran's Index. Compared with the global Moran's index, the local Moran's index (Anselin, 2010) can reflect the spatial dependence of an area and its surrounding areas [47]. The local Moran's index is used to analyze whether there is spatial heterogeneity in the development of construction industry. This is shown in the following formula:

$$
I=\left[\frac{\left(x_{i}-\bar{x}\right)}{S}\right]\left[\sum_{j=1}^{n} w_{i j}\left(x_{j}-\bar{x}\right)\right]
$$

where $n, X_{i}, \bar{x}$, and $w_{i j}$ have the same meaning as in formula (1). The larger the absolute value of $I$, the higher the degree of spatial relevance of the subregions.

If $I$ is positive, it means that local areas are low-low or high-high similarity value gathering areas; If $I$ is negative, it means that local areas are low-high or high-low similarity value gathering areas.

The Moran's scatter plot is usually used to represent the local Moran's index. The first quadrant is H-H type; that is to say, the adjacent area of high concentration of construction industry is also high. The second quadrant is $\mathrm{L}-\mathrm{H}$ type; that is to say, the adjacent areas of low industrial agglomeration area have higher agglomeration degree. The third quadrant is L-L type; that is to say, the agglomeration degree of neighboring areas of low industrial agglomeration areas is also low. The fourth quadrant is H-L type; that is to say, the agglomeration degree of adjacent areas of high industrial agglomeration areas is low. $\mathrm{H}-\mathrm{H}$ type and $\mathrm{L}-\mathrm{L}$ type indicate that the spatial correlation between regions is positive. L-H type and $\mathrm{H}-\mathrm{L}$ type indicate that the spatial correlation between regions is negative.

2.1.3. Spatiotemporal Transition Measurement Model of Spatial Agglomeration Characteristics. Basing on the original research method, Rey (2010) embeds the distance, direction, concentration, and other attributes of the geographic coordinates of the research unit in Moran's I scatter chart into the traditional Markov chain in a specific time interval, proposing a local Markov transfer and spatiotemporal transitions, used to describe the spatiotemporal evolution of Moran's I scatter diagram, and divide the spatiotemporal transitions into 4 basic types: self-transitions (I), neighborhood transitions (II), and same-direction transitions according to the transition state between each region itself and its neighbors (III), and stable transition (IV) [48], as shown in Table 1.

Based on the division of temporal and spatial transition types in the development of the construction industry, the quantile regression model can be deeply nested with it. On the one hand, the quantile regression model of construction industry development can overcome the influence of strong distribution assumptions and outliers. On the other hand, the quantile regression results can not only examine the driving effect of the construction industry agglomeration on industrial development in stages, but also take into account the dynamic characteristics of the driving effect.

Assuming that the probability distribution of industrial agglomeration $M$ is $F(M)=\operatorname{Prob}(M \leq m)$, the $\tau$ quantile of $M$ is defined as satisfying $q(\tau)=\inf \{m \mid F\}(m) \geq \tau, 0<\tau<1$, then the $\tau$ quantile $q(\tau)$ of $F(m)$ is based on the objective function that minimizes the absolute value of the weighted error. This is shown in the following formula:

$$
q(\tau)=\arg \min \zeta\left\{\tau \int_{c>\zeta}^{1}|y-\zeta| d F(c)+(1-\tau) \int_{c<\zeta}^{2}|y-\zeta d F(c)|\right\} .
$$

Specifically, according to the quantile division of the construction industry agglomeration pattern, this paper sets the high-level response and the low-level response in turn. Based on the different influence of the types of temporal and spatial transitions and driving factors in the development of the construction industry, the transition mechanism of highlow-level driving and high-low-level restriction can be constructed. The mechanism framework of temporal and spatial transition and nested analysis of construction industry development is shown in Figure 1.

2.2. Data Sources. The data in this paper come from two sources: (1) The spatial administrative boundary information comes from the National Basic Geographic Information Center. The raster data is extracted based on the research area vector boundary. (2) Social and economic data were obtained from the National Bureau of Statistics. Some missing data were supplemented by regional yearbook data. 
TABLE 1: Basic classification types of spatiotemporal transition of construction industry development.

\begin{tabular}{lccc}
\hline Type & Evolutionary manners & Type & Evolutionary manners \\
\hline I: self-transition & $\mathrm{HH}_{\mathrm{t}} \longrightarrow \mathrm{LH}_{\mathrm{t}+1} \mathrm{HL}_{\mathrm{t}} \longrightarrow \mathrm{LL}_{\mathrm{t}+1}$ & III: same direction & $\mathrm{HH}_{\mathrm{t}} \longrightarrow \mathrm{LL}_{\mathrm{t}+1} \mathrm{HL}_{\mathrm{t}} \longrightarrow \mathrm{LH}_{\mathrm{t}+1}$ \\
II: neighborhood & $\mathrm{LH}_{\mathrm{t}} \longrightarrow \mathrm{HH}_{\mathrm{t}+1} \mathrm{LL}_{\mathrm{t}} \longrightarrow \mathrm{HL}_{\mathrm{t}+1}$ & transition & $\mathrm{LL}_{\mathrm{t}} \longrightarrow \mathrm{HH}_{\mathrm{t}+1} \mathrm{LH}_{\mathrm{t}} \longrightarrow \mathrm{HL}_{\mathrm{t}+1}$ \\
transition & $\mathrm{HH}_{\mathrm{t}} \longrightarrow \mathrm{HL}_{\mathrm{t}+1} \mathrm{HL}_{\mathrm{t}} \longrightarrow \mathrm{HH}_{\mathrm{t}+1}$ & IV: stable transition & $\mathrm{HH}_{\mathrm{t}} \longrightarrow \mathrm{HH}_{\mathrm{t}+1} \mathrm{HL}_{\mathrm{t}} \longrightarrow \mathrm{HL}_{\mathrm{t}+1}$ \\
& $\mathrm{LH}_{\mathrm{t}} \longrightarrow \mathrm{LL}_{\mathrm{t}+1} \mathrm{LL}_{\mathrm{t}} \longrightarrow \mathrm{LH}_{\mathrm{t}+1}$ & & $\mathrm{LH}_{\mathrm{t}} \longrightarrow \mathrm{LH}_{\mathrm{t}+1} \mathrm{LL}_{\mathrm{t}} \longrightarrow \mathrm{LL}_{\mathrm{t}+1}$ \\
\hline
\end{tabular}

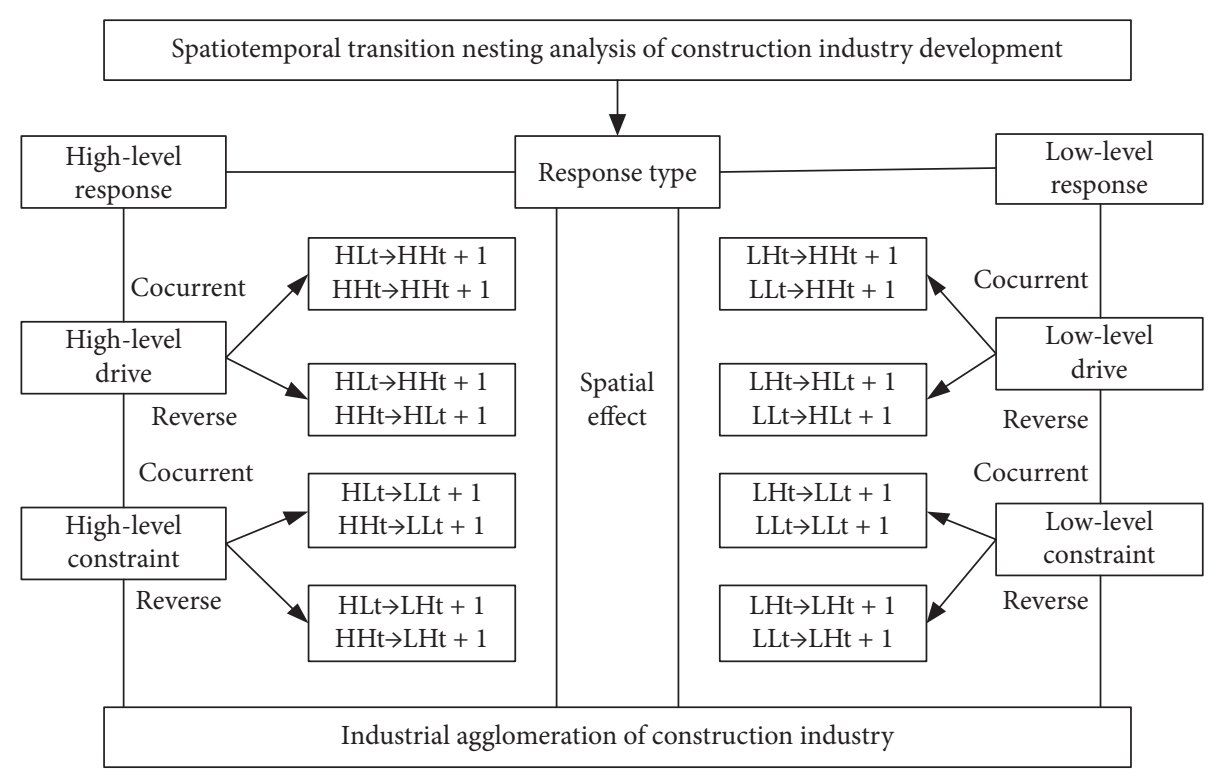

Figure 1: The mechanism of spatial and temporal transition and nested analysis of construction industry development.

This paper selects the relevant data of 31 provinces, autonomous regions, municipalities directly under the Central Government and Xinjiang Production and Construction Corps (excluding Hong Kong, Macao, and Taiwan, hereinafter referred to as the 31 regions) in China from 2010 to 2019 as the research scope.

\section{The Present Situation of the Space-Time Distribution of China's Construction Industry Agglomeration}

The development of the construction industry is influenced by geographical environment, economy, and other social factors. Based on the official data of The National Bureau of Statistics from 2010 to 2019, ArcGIS software was used to calculate the proportion of the output value of the construction industry in 31 regions of China in the national output value of construction industry, as shown in Figure 2.

Through the analysis of Figure 2, it is found the following:

On the spatial dimension, China's construction industry's overall spatial and temporal distribution presents a " $\#$ " shape with one horizontal and two belts, and the "EastWest" difference is obvious. Among them, "one horizontal line" refers to the northern horizontal line with Xinjiang, Gansu, Ningxia, Inner Mongolia, and Liaoning as the main areas. The "two belts" refer to the eastern coastal belt dominated by Shandong, Jiangsu, Shanghai, Zhejiang, Fujian, and Guangdong and the central axis belt dominated by Shaanxi, Hubei, and Chongqing. With the passage of time, the central region gradually showed "bulge" phenomenon.

The main reasons for the above phenomena are as follows:

(1) In the early stage, under the influence of eastern China's pioneering experiments and western development, the development of the construction industry in east of China, which was in the "gap," was relatively backward

(2) With the rise of central China and the further implementation of the western development strategy, China's construction industry began to shift to the west and central regions, and the concentration level of the construction industry in the central region was significantly improved, and the overall pattern showed an obvious "V" shape from decline to rise

In terms of time, the development trend of China's construction industry can be divided into two stages:

Phase I (2010-2015): during the period of steady rise, the proportion of construction output value increased steadily; Phase II (2016-2019): during the period of turbulence, the construction output ratio amplitude gradually increases, and the "instability" feature becomes increasingly prominent. In 2017 , it shows a "cliff-like" decline.

The main reasons for the above phenomena are as follows: 


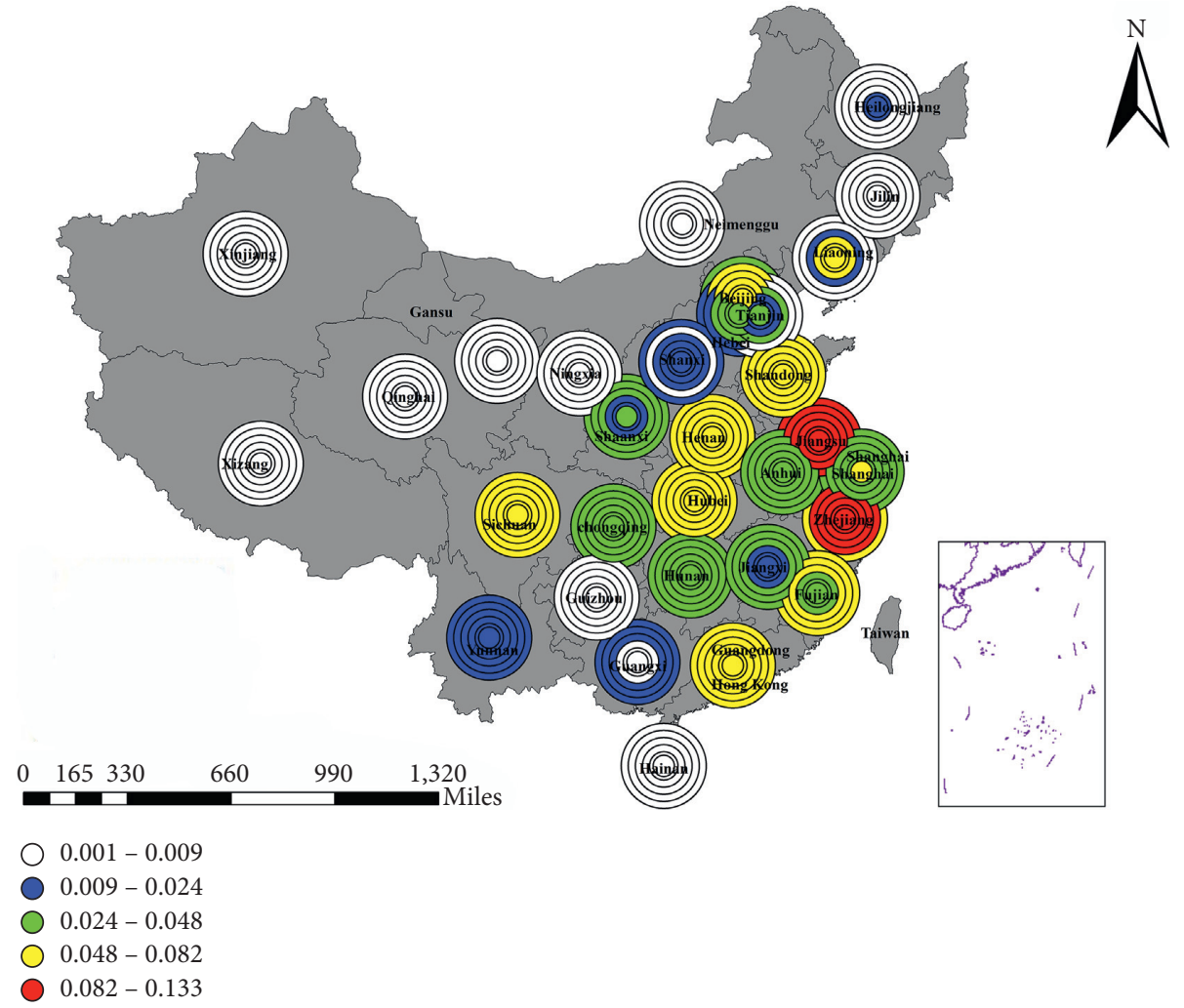

Figure 2: Time and space distribution of China's construction industry. Note. From the inside to the outside, each circle represents the period from 2010 to 2019, respectively. The proportion of construction output value decreases successively according to red, yellow, green, blue, and white.

(1) From 2010 to 2015, the eastern region took the lead in attracting the construction industry from Hong Kong, Macao, and developed countries by taking advantage of its unique geographical advantages and the opening-up policy. The construction industry developed rapidly and its agglomeration level reached the highest level in China. In recent years, with the gradual saturation of construction capital, the construction industry's development presents a downward trend.

(2) Given the most significant impact of construction dust on the regional environment, some regions should eliminate enterprises with large pollution emission in building materials and other industries. Affected by the economic downturn and the slowdown of real estate investment, the construction industry's development is slow.

\section{Analysis of the Agglomeration Characteristics of China's Construction Industry}

\subsection{Analysis of the Spatial Correlation Characteristics of China's Construction Industry Agglomeration}

4.1.1. Empirical Analysis of Global Spatial Correlation. Based on the statistical data of construction industry development in 31 regions of China from 2010 to 2019, the overall Moran's index is introduced to analyze the overall differentiation characteristics of China's construction industry spatial agglomeration. The measurement results are shown in Table 2.

According to the analysis in Table 2 about China's construction industry in the past 10 years,

(1) the global Moran's index is between 0 and 0.5 , and the overall trend is increasing from small to large. It shows that the positive spatial autocorrelation characteristics of China's construction industry development area are apparent, the spatial correlation is gradually growing, and the regional connection is becoming closer;

(2) regional development as a whole presents the characteristics of high-high and low-low spatial agglomeration. It shows that the regional construction industry's development level is closely related to the development of the surrounding areas. On the one hand, it may be restricted by the development of the surrounding areas, and on the other hand, it will stimulate the development of the surrounding areas;

(3) the global Moran's index differs slightly at different times, further verifying that the development of the construction industry has good stability.

4.1.2. Empirical Analysis of Local Spatial Correlation. The global Moran's index mainly measures the overall agglomeration correlation degree of the development level of 
TABLE 2: Global autocorrelation Moran's index of changes in China's construction industry.

\begin{tabular}{lccccccc}
\hline Years & $\begin{array}{c}\text { Moran's } \\
\text { index }\end{array}$ & $E(\mathrm{I})$ & $P$ & Years & $\begin{array}{c}\text { Moran's } \\
\text { index }\end{array}$ & $E(\mathrm{I})$ & $P$ \\
\hline 2010 & 0.2714 & -0.03 & 0.019 & 2015 & 0.4687 & -0.03 & 0.001 \\
2011 & 0.3494 & -0.03 & 0.018 & 2016 & 0.2637 & -0.03 & 0.020 \\
2012 & 0.3874 & -0.03 & 0.009 & 2017 & 0.2588 & -0.03 & 0.020 \\
2013 & 0.2199 & -0.03 & 0.026 & 2018 & 0.3294 & -0.03 & 0.013 \\
2014 & 0.4458 & -0.03 & 0.008 & 2019 & 0.3422 & -0.03 & 0.024 \\
\hline
\end{tabular}

China's construction industry, but it cannot reveal the agglomeration correlation degree of local areas in adjacent spaces. To further analyze the spatial agglomeration and differentiation characteristics of China's construction industry. This paper uses the local Moran's index to describe the spatial heterogeneity of the development of the construction industry in each study area and its adjacent areas. Generate Moran's scatter plot and LISA cluster plot to judge the spatial correlation degree of the construction industry's development level between regions. The measurement result is shown in Figure 3.

Through the analysis of Figure 3, the following is found:

Moran's index scatter plot shows obvious "high-low" and "low-high" agglomeration characteristics gradually weakening; "high-high" and "low-low" agglomeration characteristics are gradually strengthening. The spatial heterogeneity is weak, and it has a significant "Matthew effect." It shows that the agglomeration level of the regional construction industry is restricted and driven by the development of the surrounding area's construction industry and is highly consistent with the spatial agglomeration level of the surrounding area.

The LISA cluster map of China's construction industry is mainly divided into high-high agglomeration $(\mathrm{H}-\mathrm{H})$, lowhigh agglomeration (L-H), low-low agglomeration (L-L), and high-low agglomeration (H-L), as shown in Table 3.

(1) In terms of local space, Shandong, Jiangsu, Zhejiang, Shanghai, Xinjiang, Tibet, Beijing, Tianjin, Hebei, and Guangdong have significant statistical significance, indicating that the development of the construction industry in these regions has a guiding effect on the development of China's construction industry.

(2) $\mathrm{H}-\mathrm{H}$ agglomerations are mainly distributed in the Yangtze River Delta Urban Agglomeration. These areas together form a "high-value club" for the development of the construction industry. L-L clusters are mainly distributed in northwest China, and the area is gradually shrinking. Hebei, Shanxi, and other areas in L-H have relatively high development in the construction industry, but they are easily affected by the negative effects of surrounding areas and weaken. Guangdong and other regions in the H-L region have a favorable location advantage of being "proliferated," and it is necessary to strengthen the connection with the surrounding provinces with low development of construction industry.
(3) Some regions fall into the second and fourth quadrants, indicating spatial differences in the development of China's construction industry. From the change of Moran's scatter chart and LISA cluster chart of the construction industry from 2010 to 2019, it can be seen that the development level index value of the construction industry falling in the first and third quadrants has increased, mainly in the eastern coastal cities. It shows that the eastern coastal areas of China rely on their unique location, economy, and transportation advantages; through the polarization effect, the building resources are continuously promoted to gather in the direction of "peripherycenter"; as a result, the level of agglomeration of the construction industry continues to increase, the spatial connections between provinces and cities are getting closer, and the spatial heterogeneity continues to shrink.

4.2. China Building Industry Cluster Transition Characteristics of Time and Space Analysis. The researches on the spatial distribution characteristics of construction industry development are discussed in this paper; the spatial distribution is variable. Therefore, this paper adopts the time-space transition measure method for in-depth analysis and selects the stability index of spatial agglomeration of the construction industry, namely, spatial cohesion, to measure the transition state of the regional construction industry. Its value is equal to the proportion of a certain transition type in the study period's total number of transitions. According to the basic types of temporal and spatial transitions, the construction industry's local Moran's index transition probability matrix can be obtained, as shown in Table 4 .

Through the analysis of Table 4, the following is found:

(1) The spatial structure of construction industry in 31 regions of China is stable as a whole, showing an obvious inert transition. The transition probability of type I, type II, and type III transition is only 0.18 , while the space transition probability of type IV is 0.82 , and the corresponding spatial cohesion is $82 \%$, which indicates that the regional development of China's construction industry has strong path dependence and spatial locking.

(2) "Self-transition" and "neighborhood transition" are the two time-space transition modes that appear least frequently in China's construction industry's regional development. It shows that the development of the regional construction industry will have mutual influence on the surrounding areas. The construction industry's development factors will have a spillover effect and demonstration effect in the neighboring regions.

(3) The cotransition of both regions and their neighborhoods is the least common, which further verifies the atypical characteristics of the development of regional construction industry. 

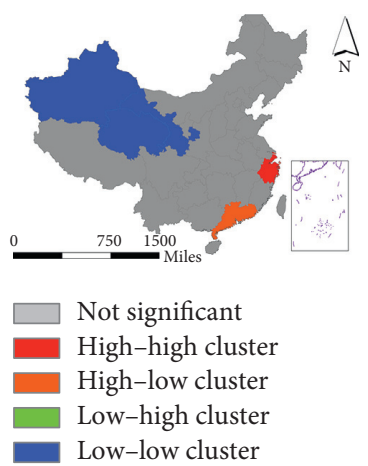

(a)

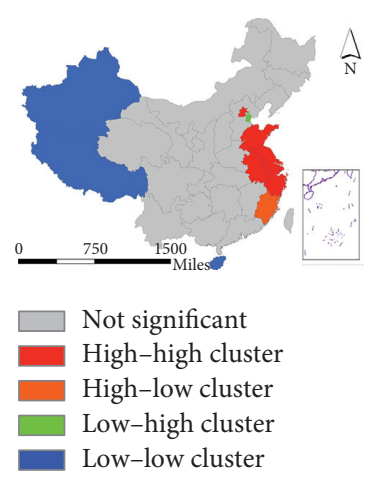

(e)

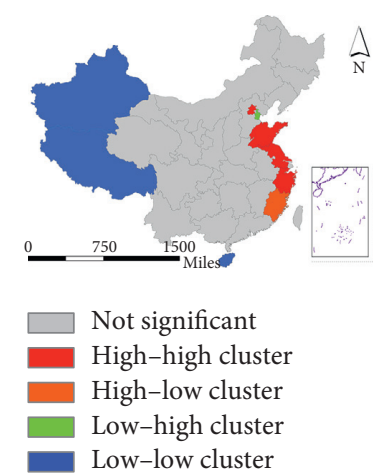

(b)

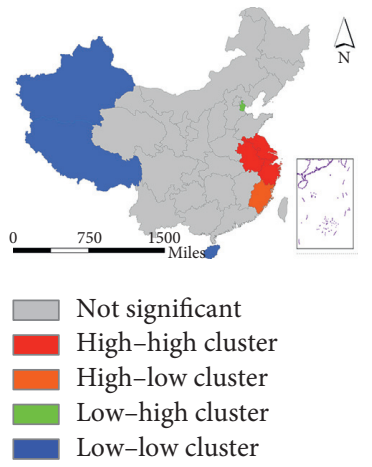

(f)

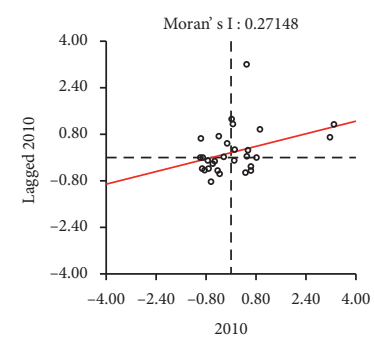

(c)

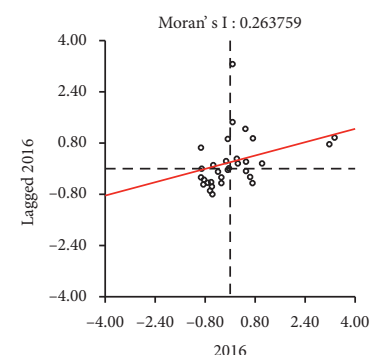

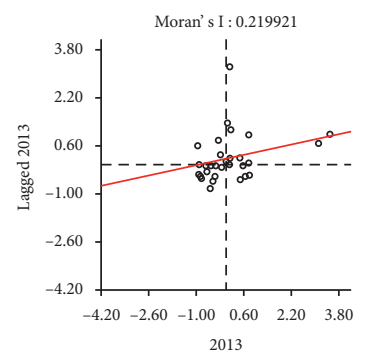

(d)

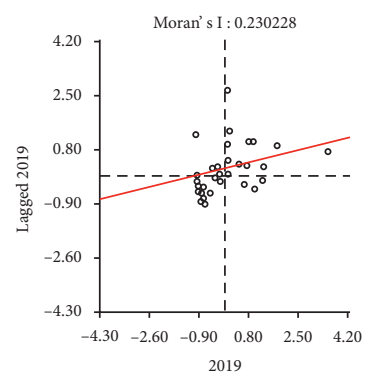

(h)

FIgURE 3: Spatial clustering characteristics of China's construction industry.

TABle 3: Moran's index scattered distribution map province distribution.

\begin{tabular}{|c|c|c|c|c|c|}
\hline Time & $\mathrm{H}-\mathrm{H}$ & L-L & $\mathrm{L}-\mathrm{H}$ & $\mathrm{H}-\mathrm{L}$ & $\begin{array}{c}\text { Cross } \\
\text { quadrant }\end{array}$ \\
\hline 2010 & $\begin{array}{l}\text { Beijing, Tianjin, } \\
\text { Shanghai, Zhejiang, } \\
\text { Fujian, Jiangsu }\end{array}$ & $\begin{array}{l}\text { Jilin, Heilongjiang, Inner Mongolia, Jiangxi, } \\
\text { Hubei, Sichuan, Guizhou, Yunnan, Tibet, } \\
\text { Xinjiang, Ningxia, Gansu, Qinghai, Shaanxi, } \\
\text { Henan }\end{array}$ & $\begin{array}{l}\text { Hubei, } \\
\text { Shanxi, } \\
\text { Guangxi }\end{array}$ & $\begin{array}{l}\text { Anhui, Hunan, } \\
\text { Guangdong, } \\
\text { Chongqing, Liaoning }\end{array}$ & $\begin{array}{l}\text { Hainan, } \\
\text { Shandong }\end{array}$ \\
\hline 2013 & -Fujian, +Shandong & + Anhui, + Hunan & & -Anhui, -Hunan & $\begin{array}{l}\text { +Fujian, } \\
\text {-Shandong }\end{array}$ \\
\hline 2016 & +Shandong, -Tianjin & +Hainan, -Hubei, -Shaanxi & +Tianjin & $\begin{array}{c}\text { +Fujian, +Hubei, } \\
\text { +Shaanxi }\end{array}$ & $\begin{array}{l}\text {-Fujian, } \\
\text {-Hainan }\end{array}$ \\
\hline 2019 & & +Liaoning, -Jiangxi & & -Liaoning, +Jiangxi & \\
\hline
\end{tabular}

TABLE 4: Construction industry's local Moran's index transition probability matrix.

\begin{tabular}{|c|c|c|c|c|}
\hline Type & $\mathrm{H}-\mathrm{H}_{\mathrm{t}+1}$ & $\mathrm{H}-\mathrm{L}_{\mathrm{t}+1}$ & $\mathrm{~L}-\mathrm{L}_{\mathrm{t}+1}$ & $\mathrm{~L}-\mathrm{H}_{\mathrm{t}+1}$ \\
\hline $\mathrm{H}-\mathrm{H}_{\mathrm{t}}$ & IV $(0.28)$ & II $(0.011)$ & I $(0.016)$ & III $(0.005)$ \\
\hline $\mathrm{H}-\mathrm{L}_{\mathrm{t}}$ & II $(0.011)$ & IV $(0.16$ & III (0.003) & I (0.03) \\
\hline $\mathrm{L}-\mathrm{L}_{\mathrm{t}}$ & I $(0.008)$ & III $(0.003)$ & IV $(0.052)$ & II $(0.016)$ \\
\hline $\mathrm{L}-\mathrm{H}_{\mathrm{t}}$ & III $(0.008)$ & $\mathrm{I}(0.03)$ & II $(0.016)$ & IV $(0.321)$ \\
\hline
\end{tabular}

Based on the nested analysis framework of spatiotemporal transition and spatial quantile regression of the construction industry, the driving paths of the construction industry in different regions are different, and the regions are further divided into four response modes, namely, low-level restriction, low-level drive, high-level restriction, and highlevel drive. The empirical results are shown in Table 5.
Through the analysis of Table 4, the following is found: The development type of China's construction industry is mainly driven by high level and restricted by low level. The high-level types are mainly concentrated in the eastern developed areas, and the low-level types are mainly in the western region.

(i) Low-level constraints: except for Heilongjiang, other provinces are hindered by their own development and the construction industry in neighboring regions, and the development situation is not optimistic.

(ii) Low-level driving type: except for Sichuan, all other areas are driven in the same direction. At the initial stage, they are at a low level. However, both it and the neighboring areas are in good development 
TABLE 5: China's construction industry development spatiotemporal response mode.

\begin{tabular}{|c|c|c|c|}
\hline Pattern & $\begin{array}{l}\text { Response } \\
\text { patterns }\end{array}$ & $\begin{array}{l}\text { The evolution } \\
\text { way }\end{array}$ & Provinces \\
\hline \multirow[b]{2}{*}{ Self-transition } & Low-level drive & $\mathrm{LL}_{\mathrm{t}} \longrightarrow \mathrm{HL}_{\mathrm{t}+1}$ & Jiangxi, Shanxi \\
\hline & $\begin{array}{l}\text { High-level } \\
\text { restriction }\end{array}$ & $\begin{aligned} \mathrm{HL}_{\mathrm{t}} & \longrightarrow \mathrm{LL}_{\mathrm{t}+1} \\
\mathrm{HH}_{\mathrm{t}} & \longrightarrow \mathrm{LH}_{\mathrm{t}+1}\end{aligned}$ & Hainan, Anhui, Hunan, Hubei \\
\hline \multirow{2}{*}{$\begin{array}{l}\text { Neighborhood } \\
\text { transition }\end{array}$} & $\begin{array}{l}\text { High-level } \\
\text { restriction }\end{array}$ & $\mathrm{HL}_{\mathrm{t}} \longrightarrow \mathrm{HH}_{\mathrm{t}+1}$ & Shandong \\
\hline & $\begin{array}{l}\text { Low-level } \\
\text { restriction }\end{array}$ & $\mathrm{LL}_{\mathrm{t}} \longrightarrow \mathrm{LL}_{\mathrm{t}+1}$ & $\begin{array}{l}\text { Ningxia, Henan, Qinghai, Gansu, Xinjiang, Tibet, Heilongjiang, Yunnan, Jilin, } \\
\text { Inner Mongolia, Guizhou, Guangxi, Sichuan, Shanxi }\end{array}$ \\
\hline \multirow{3}{*}{ Stable transition } & Low-level drive & $\mathrm{LH}_{\mathrm{t}} \longrightarrow \mathrm{LH}_{\mathrm{t}+1}$ & Hebei \\
\hline & $\begin{array}{l}\text { High-level } \\
\text { restriction }\end{array}$ & $\mathrm{HL}_{\mathrm{t}} \longrightarrow \mathrm{HL}_{\mathrm{t}+1}$ & Tianjin, Liaoning \\
\hline & High-level drive & $\mathrm{HH}_{\mathrm{t}} \longrightarrow \mathrm{HH}_{\mathrm{t}+1}$ & Beijing, Jiangsu, Zhejiang, Shanghai, Guangdong, Chongqing, Fujian \\
\hline
\end{tabular}

condition, and they are jointly transformed to a high-level state.

(iii) High-level constraint: Tianjin, Liaoning, and Henan all changed from high level to low level, but their adjacent units were not affected and remained at high level, which played a driving role in the development of low-level areas.

(iv) High-level driving type: except for Chongqing, other areas have a good development trend in the future, forming high-level agglomeration areas.

\section{Conclusion and Discussion}

5.1. Conclusion. Based on the relevant data of the total building output value of 31 regions in China, this study uses spatial correlation and temporal and spatial transition measurement models to study the spatial pattern of industrial agglomeration in China, and the following research conclusions are obtained:

(1) The agglomeration of China's construction industry presents strong spatial differences. Taking HeiheTengchong Line as the boundary, the distribution difference between southeast and northwest is obvious. The southeast always occupies a significant advantage.

(2) China's construction industry has significant positive spatial autocorrelation. Among them, $\mathrm{H}-\mathrm{H}$ and $\mathrm{L}-\mathrm{L}$ are the most important spatial clustering types. They show strong qualitative characteristics of spatial lock in spatial geographical distribution.

(3) The high-concentration areas of China's construction industry are mainly distributed in the Yangtze River Delta Urban Agglomeration and Pearl River Delta Urban Agglomeration, such as Guangdong, Zhejiang, and Jiangsu. The low-level agglomeration areas mainly include the Lanzhou-Xining Urban Agglomeration and the Ningxia Urban Agglomeration along the Yellow River. There are great regional differences in the development of the internal construction industry in western China, Sichuan, Shaanxi, and other regions that performed well. The construction industry in Tibet, Ningxia, and other regions has low-level agglomeration density and relatively backward development.

(4) The agglomeration of China's construction industry presents strong spatiotemporal path-dependent characteristics. In terms of time dimension, the construction industry in adjacent areas has significant positive correlation. In spatial dimension, the spillover effect of spatial agglomeration of construction industry is uncertain. It shows that China's construction industry can influence the industrial development of surrounding areas through demonstration. It also shows that China's construction industry is driven or restricted by the industrial development level of surrounding areas, forming the linkage effect between regions.

(5) The time-space transition of China's construction industry is dominated by "stable transition" mode. And it is supplemented by "self-transition" and "neighborhood transition" mode. The transition inertia is significant. The regional development has strong path dependence and spatial locking characteristics. It leads to the coexistence of "agglomeration" and "differentiation" in the space of the construction industry. The eastern region as a whole shows a high level of driving. The western region shows a stable low-level restriction state.

5.2. Discussion. Regarding the problem of industrial distribution and agglomeration, domestic and foreign researches are basically concentrated in general industries such as manufacturing and tertiary industries. Due to the uniqueness and uniqueness of the output of the construction industry, many scholars believe that the industrial agglomeration phenomenon of the general industry and the tertiary industry is unlikely to occur in the construction industry (Zhen et al., 2010) [49]. However, the economic interaction in regions, coupled with the factors such as industrial coordination and regional policies, has led to a gradually increasing in the regional development level of the construction industry (Liu et al., 2015) [50]. With the 
upgrading and transformation of construction industrialization, as an important link in the process of industrialization, the phenomenon of industrial agglomeration has emerged. Xiao (2013), Zhang (2010), Dai (2010), Hong (2020), etc. used a variety of methods, respectively, to measure the development of the construction industry in different regions; it proved that the construction industry has a certain degree of agglomeration in space [51-54]. This provides theoretical and practical support for the research, but there are some shortcomings. There are few research results on the characteristics of the construction industry agglomeration. Most of the researches on the time evolution characteristics of the construction industry agglomeration lack spatial perspective, causing the research results to be more abstract.

This research mainly uses the latest construction industry-related data to describe the complete process of the spatial evolution of the Chinese construction industry in the past 10 years and summarizes the significant temporal and spatial differentiation of the spatial evolution of the Chinese construction industry in different regions. Through the analysis of the spatiotemporal pattern of construction industry agglomeration, it plays an important role in predicting the regional development trend, recognizing and grasping the regional development stage, adjusting the regional spatial development strategy, and improving the allocation of industrial resources in time, also in favor of promoting the urban industrial transformation and its spatial restructuring. When discussing its regional differences and spatial structure, it breaks the long-standing limitation of agglomeration characteristics with time as the axis. Based on the perspective of spatial and temporal dimensions, it provides theoretical analysis of spatial economics and new economic geography for the development of the construction industry, thus making up for the academic deficiencies.

Therefore, the empirical research conclusions of this paper have important guiding significance for promoting the improvement of the agglomeration level of China's construction industry, optimizing the path selection for the transition of the construction industry to a state of high agglomeration, and the layout of industrial development decisions.

First of all, the analysis of the space-time distribution of China's construction industry agglomeration will play a good role in guiding the macro layout of China's construction industry. This study makes a comprehensive comparison of the development of the construction industry in various regions of China and finds that the agglomeration of the construction industry in China presents strong spatial differences. Based on this difference, the regional development strategy of the construction industry should build a growth pole of the construction industry in the Yangtze River Delta Urban Agglomeration and Pearl River Delta Urban Agglomeration, with Jiangsu, Guangdong, and Zhejiang as the main regions. These areas are multicore central urban agglomeration with a higher degree of openness and a wider radiation range. Through the radiation linkage of multiple cores, they can promote the rapid development of the entire urban agglomeration and even across regions. With the implementation of the strategy of western development, the construction industry in western China has seen significant substantial growth, but there is still a gap between western China and eastern China. Therefore, the allocation of construction industry resources should be optimized and differentiated policies should be adopted to improve the unbalanced development of the construction industry. Sichuan in the western region should make use of its own advantages to become a pole of growth in the western region. By promoting the growth of other provinces in western China through the diffusion of resources and technologies, the construction industry can be transformed to a state of high concentration.

Secondly, through the analysis of the overall and local characteristics of the construction industry, it has guiding significance for the scientific formulation of the development policy of the construction industry. The research found that the spatial correlation between the construction industry in Chinese provinces was obvious. The development of the construction industry has formed a pattern of positive correlation between high output and high spatial correlation in the eastern region and low output and low spatial correlation in the central and western regions. The analysis results show that the neighbor effect is significant. Therefore, the development planning of the construction industry in each region should pay attention to the spatial characteristics of cross regions. From a broader point of view to study the coordinated development of regional architecture, actively seek cross-regional cooperation and mutual assistance to form a win-win situation. First of all, strengthening regional cooperation in the construction industry, especially in the developed areas to implement a development policy conducive to "rich neighbors," can bring win-win results. Secondly, low-level and low-growth areas appear in the form of agglomeration in space. Selecting agglomeration areas as the primary development object and adopting regional development policies that promote the common growth of agglomeration areas can produce better results. Thirdly, the spatial correlation of regional construction growth is affected by geographical factors such as relative location and distance. This indicates that sufficient attention should be paid to geographical factors (spatial correlation and heterogeneity) in the formulation of corresponding macroeconomic policies for construction. Only in this way can reasonable policies be formulated.

In sum, this research supports the exploration of China's construction industry agglomeration theory. Research perspectives and research methods are applicable to exploring the development of construction industry agglomeration in any country according to the development of national conditions to determine the specific research content.

A large part of the empirical research in this study uses spatial econometric analysis methods. This article selects the most commonly used distance spatial weight matrix in spatial measurement. This matrix only considers the distance relation between provinces and is not necessarily the most appropriate matrix form to measure the spatial arrangement consistency of the construction industry. Therefore, the future research can further explore the 
construction and selection of spatial matrix and choose the most suitable analysis method for the actual situation of this study.

\section{Data Availability}

The total construction output value data of 31 regions in China can be obtained for free on the official website of the National Bureau of Statistics of China (https://data.stats.gov. $\mathrm{cn} /$

\section{Conflicts of Interest}

The authors declare that they have no conflicts of interest regarding the publication of this paper.

\section{Acknowledgments}

This work was supported by the Beijing Municipal Natural Science Foundation (no. 9202006), the Excellent Talent Project of North China University of Technology in 2019 (no. 216051360020XN225/004), and the National Key Research and Development Program of China (no. 2016YFC0701808-02). The authors acknowledge and are grateful for the funding.

\section{References}

[1] F. Maurel and B. Sédillot, "A measure of the geographic concentration in French manufacturing industries," Regional Science and Urban Economics, vol. 29, no. 5, pp. 575-604, 1999.

[2] M. Wen, "Relocation and agglomeration of Chinese industry," Journal of Development Economics, vol. 73, no. 1, pp. 329-347, 2004.

[3] P. Krugman, "Increasing returns and economic geography," Journal of Political Economy, vol. 99, no. 3, pp. 483-499, 1991.

[4] M. Fujita, P.-R. Krugman, and A.-J. Venables, The Spatial Economy: Cities, Regions and International Trade, The MIT Press, Cambridge, MA, USA, 1999.

[5] S. Dirk, "Erratum: where do cities form? A geographical agglomeration model for Europe," Journal of Regional Science, vol. 46, no. 3, pp. 602-603, 2006.

[6] K. Ikeda, K. Murota, and Y. Takayama, "Stable economic agglomeration patterns in two dimensions: beyond the scope of central place theory," Journal of Regional Science, vol. 57, no. 1, pp. 132-172, 2017.

[7] G. H. Searle, "Changes in producer services location, Sydney: globalisation, technology and labour," Asia Pacific Viewpoint, vol. 39, no. 2, pp. 237-255, 1998.

[8] J. Hoffmann, S. Hirsch, and J. Simons, "Identification of spatial agglomerations in the German food processing industry," Papers in Regional Science, vol. 96, no. 1, pp. 139-162, 2017.

[9] X. Zhao, M. Zhang, Y. Li, X. Huang, and L. Zhang, "Urban residential land expansion and agglomeration in China: a spatial analysis approach," Environment Development and Sustainability, vol. 22, no. 1, pp. 5317-5335, 2019.

[10] C.-H. Hu, W.-D. Liu, Y.-Q. Jia, and Y.-Y. Jin, "Characterization of territorial spatial agglomeration based on POI data: a case study of Ningbo City, China," Sustainability, vol. 11, no. 18, pp. 5083-5097, 2019.
[11] T.-L. Zhang and L. Ge, "A supplemental indicator of highvalue or low-value spatial clustering," Geographical Analysis, vol. 38, no. 2, pp. 209-225, 2010.

[12] H. Kang, "Detecting agglomeration processes using spacetime clustering analyses," The Annals of Regional Science, vol. 45, no. 2, pp. 291-311, 2010.

[13] E.-L. Li, "Evolution and innovation and development mechanism of agricultural industry cluster in China-taking Shouguang model vegetable industry cluster as an example," Geoscience, vol. 40, no. 4, pp. 617-627, 2020.

[14] J.-W. Zhao, Y.-F. Chen, L. Yu, and C.-B. Yin, "Spatial and temporal characteristics and influencing factors of pig breeding industry in China," Economic Geography, vol. 39, no. 2, pp. 180-189, 2019.

[15] C.-F. He and F.-H. Pan, "The trends of geographical agglomeration of manufacturing sectors in China and the explanations," South China Journal of Economics, vol. 6, pp. 38-52, 2011.

[16] C.-F. He and X.-Z. Xie, "Geographical concentration and provincial specialization of Chinese manufacturing industries," Journal of Geography, vol. 61, no. 2, pp. 212-222, 2006.

[17] X.-C. Bi, R.-X. Gu, Q. Su, and B.-Q. Lin, "The agglomeration of manufacturing industry and the evolution of geographical pattern in Jiangsu province," East China Economic Management, vol. 32, no. 7, pp. 12-21, 2018.

[18] B.-Z. Yi and C.-Y. Zhang, "A study of spatio-temporal pattern evolution of Chinese high-tech industry cluster," Study \& Exploration, vol. 297, no. 4, pp. 115-121, 2020.

[19] X. Zhang, E.-S. Zhong, X.-H. Zhang, and S. H. Wang, "Spatial distribution and clustering of commercial network in Beijing during 2004-2008," Progress in Geography, vol. 32, no. 8, pp. 1207-1215, 2013.

[20] G. Li, W.-Y. Chen, L. Yang, Q. Liu, and X. Chen, "Spatial pattern and agglomeration mode of parcel collection and delivery points in Wuhan city," Progress in Geography, vol. 38, no. 3, pp. 407-416, 2019.

[21] X. Tong, T. Zou, and Y.-P. Tong, "The study of Jiangxi province's construction-spatial-cluster based on the analysis of Gini coefficient," Science and Technology Management Research, vol. 7, no. 32, pp. 187-190, 2012.

[22] J.-D. Sun, X. Chen, and Q. Nie, "Analysis of industrial agglomeration effect in Shanghai construction industry," Shanghai Management Science, vol. 3, pp. 87-91, 2015.

[23] L.-K. Zhao, Y.-Q. Liu, and J.-S. Tian, "Spatiotemporal evolution law and output prediction of construction waste in the people's republic of China," Waste Management \& Research, Article ID 985605, 2021.

[24] M. Xie, H.-Y. Zhao, N.-N. Zhu et al., "An analysis on the agglomeration of tertiary industries in Zhejiang province," Economic Geography, vol. 35, no. 9, pp. 96-102, 2015.

[25] C.-V. Egeraat and D. Curran, "Spatial concentration in the Irish pharmaceutical industry: the role of spatial planning and agglomeration economies," Tijdschrift voor Economische en Sociale Geografie, vol. 104, no. 3, pp. 338-358, 2013.

[26] G. Bruckmann, "A generalized concept of concentration and its measurement," Statistische Hefte, vol. 12, no. 3-4, pp. 204-223, 1971.

[27] C. Dagum, "A new approach to the decomposition of the Gini income inequality ratio," Empirical Economics, vol. 22, no. 4, pp. 515-531, 1997.

[28] G. Ellison and E.-L. Glaeser, "Geographic concentration in U.S. Manufacturing industries: a dartboard approach," Journal of Political Economy, vol. 105, no. 5, pp. 889-927, 1999. 
[29] Y.-F. Liu and H.-S. Su, "Containment control of second-order multi-agent systems via intermittent sampled position data communication," Applied Mathematics and Computation, vol. 362, Article ID 124522, 2019.

[30] Y. Liu and H. Su, "Some necessary and sufficient conditions for containment of second-order multi-agent systems with sampled position data," Neurocomputing, vol. 378, pp. 228237, 2020.

[31] B. D. Ripley, "Modelling spatial patterns," Journal of the Royal Statistical Society: Series B (Methodological), vol. 39, no. 2, pp. 172-192, 1977.

[32] H.-H. Yuan, H. Zhang, and H.-Y. Zeng, "Measuring localization of manufacturing industries and its dynamics-using Beijing firm-level data," China Industrial Economics, vol. 9, pp. 38-50, 2014.

[33] P. A. P. Moran, "Notes on continuous stochastic phenomena," Biometrika, vol. 37, no. 1-2, pp. 17-23, 1950.

[34] D. W. S. Wong, "Several fundamentals in implementing spatial statistics in GIS:using centrographic measures as examples," Annals of GIS, vol. 5, no. 2, pp. 163-174, 1999.

[35] G. Duranton and H. G. Overman, "Testing for localization using micro-geographic data," The Review of Economic Studies, vol. 72, no. 4, pp. 1077-1106, 2005.

[36] G. Duranton and H. G. Overman, "Exploring the detailed location patterns of U.K. manufacturing industries using microgeographic data*," Journal of Regional Science, vol. 48, no. 1, pp. 213-243, 2008.

[37] E. Marcon and F. Puech, "Measures of the geographic concentration of industries: improving distance-based methods," Journal of Economic Geography, vol. 10, no. 5, pp. 745-762, 2009.

[38] G. Lang, E. Marcon, and F. Puech, "Distance-based measures of spatial concentration: introducing a relative density function," The Annals of Regional Science, vol. 64, no. 2, p. 243, 2020.

[39] E. Howard, C. Newman, and F. Tarp, "Measuring industry coagglomeration and identifying the driving forces," Journal of Economic Geography, vol. 16, no. 5, pp. 1055-1078, 2016.

[40] K. Kopczewska, "Comment to XCL co-agglomeration index: distance-weighted improved DCL index," Papers in Regional Science, vol. 95, no. 4, pp. 903-910, 2016.

[41] W. Zhen, "Spatial agglomeration level measurement and evaluation of manufacturing in Fujian Province," Economic Geography, vol. 32, no. 7, pp. 74-80, 2012.

[42] L. Qiu and C.-L. Fang, "Comprehensive assessment on the spatial agglomeration of producer services in Beijing," Economic Geography, vol. 32, no. 1, pp. 99-110, 2013.

[43] Q.-B. Guo and Z.-H. Zhang, "Spatiotemporal evolution of factors aggregating ability in urban agglomeration in the middle reaches of the Yangtze River," Acta Geographica Sinica, vol. 72, no. 10, pp. 1746-1761, 2017.

[44] X.-W. Liu, "Measurement on China's service industry agglomeration and urban productivity: taking 233 prefectural and above level cities for example," Urban Problems, vol. 11, pp. 59-68, 2019.

[45] G.-F. Jenks, "The data model concept in statistical mapping," International Yearbook of Cartography, vol. 7, pp. 186-190, 1967.

[46] L. Anselin and R.-J. Florax, "Small sample properties of tests for spatial dependence in regression models: some further results," in New Directions in Spatial Econometrics, pp. 21-74, Springer-Verlag, Berlin, Germany, 1995.

[47] L. Anselin, "Local indicators of spatial association-lisa," Geographical Analysis, vol. 27, no. 2, pp. 93-115, 2010.
[48] S. J. Rey, "Spatial empirics for economic growth and convergence," Geographical Analysis, vol. 33, no. 3, pp. 195-214, 2010.

[49] X. Zheng and Z.-N. Liu, "Considerations on the gini coefficient and industrial agglomeration development of the construction industry in the eight Southeastern Provinces," in Proceedings of the 2010 International Conference On Information Technology \& Scientific Management, IEEE, Tianjin, China, December 2010.

[50] B.-S. Liu and B. Xue, "Analysis of the three-dimensional system of industry linkages with spatial difference for the Chinese regional construction industry," Journal of Chongqing University (Social Science Edition), vol. 21, no. 1, pp. 16-22, 2015.

[51] L. Xiao and Y.-C. Guo, "Spatial agglomeration analysis of total output value of construction industry in East China," CoOperative Economy \& Science, vol. 3, pp. 24-25, 2013.

[52] M. Zhang, D.-Y. Qiao, and Y.-A. Dai, "A spatial econometric analysis of the construction's differences in China's provincial regions," Scientific Decision Making, vol. 3, pp. 87-93, 2010.

[53] Y.-A. Dai and C. Chen, "Spatial econometric analysis of regional differences in China's construction industry development," Statistics \& Information Forum, vol. 5, pp. 53-58, 2010.

[54] J.-K. Hong, Z.-J. Huang, J.-D. Yao, and C.-Y. Wang, "Study on the construction agglomeration of the Yangtze River economic belt and its spillover effect," Construction Economy, vol. 41, no. 12, pp. 21-25, 2020. 